\title{
Factors influencing adaptation of innovations in small ruminant production in the TRC3 Region in Turkey
}

\author{
Veysi Acıbuca ${ }^{1 *}$, Dilek Bostan Budak ${ }^{2}$ \\ ${ }^{1}$ Mardin Artuklu University, KIzIltepe Vocational School, Department of Plant and Animal Production/Organic Agriculture PR., 47000, \\ Mardin/Turkey, ${ }^{2}$ Cukurova University, Faculty of Agriculture, Department of Agricultural Economics, 01330, Adana/Turkey
}

\section{A B S T R A C T}

\begin{abstract}
This study investigated the socio-economic factors affecting the adoption of innovation in small ruminant production in TRC3 region in Turkey. Stratified random sampling technique was used to select 366 small ruminant farmers from the region. Semi-structured questionnaire was used to collect main data for the study. Data collected were analyzed using descritive statistics, t-tests and multiple linear regression analysis. Results of the study showed that the farmers had a mean age of 45,8 years and $97,0 \%$ were male. Traditional production was dominant among the small ruminant producers and as the number of animal increases the income increases $(p<0,01)$. Out of twelve independent variables, eight of them were statistically significant on multiple linear regression analysis. The F-statistics was statistically significant at $1 \%$ level on communication behavior and animal health practices; $5 \%$ level on age, breeding reasons, milking way, produced products and fold type. The coefficient of multiple determination (R2) value was estimated to be 0,470 this implies that $47,0 \%$ of total variation in the output of small ruminant production was accounted for by the independent variables that were fitted into the model. The main problems of small ruminant production were high feed prices, high deaths of lamps/goat, insufficient use of pastures because of security problems and lack of shepherd due to young people unwillingness to live in rural areas.
\end{abstract}

Keywords: TRC3 region; Small ruminant; Innovation; Regression analysis; Turkey

\section{INTRODUCTION}

Animal production is a sub-sector of agricultural activity and it plays an important role in every country's economy regardless of development levels. Animal production contributes significantly to the national economy, first and foremost due to its role in human nutrition, but also by supporting the industrial network, preventing rural poverty and decreasing seasonally bound income for people living in the rural areas. Animal husbandry is vitally important for developing countries where food security is not entirely assured. In developed countries, more than half of agricultural income is derived from animal husbandry activities; despite being home to around $30-40 \%$ of the world's cattle population, these countries create $75-80 \%$ of the world's animal production (Sakarya and Aydın, 2011). Demand for animal products is soaring globally due to increasing population, urbanisation, and improved income levels (Delgado et al., 2001). Demand for animal products is set to rise by around $70 \%$ by 2050 to increase the sector's budget to 9.6 Billion Euros (FAO, 2014).
Small ruminant farming is a sub-sector of husbandry; it is not only one of the oldest economic activities known to humanity but also plays an important part in the global economy by producing meat, milk, dairy products, and byproducts such as leather, hair, and wool. Due to requiring low maintenance, allowing farmers to make use of outlying fields, and having a low cost of investment, sheep and goat farming is beneficial for raising the living standards of the rural poor, as well as playing an important part in meeting the demand for animal products. In addition to contributing to food safety, human health, and the economy, small ruminant farming can be an important determining factor of social status, particularly in African countries (Thornton, 2010).

According to data obtained by the Food and Agriculture Organisation (FAO), there are an estimated 1.209.000.000 heads of sheep and 1.046.000.000 heads of goat worldwide. China is the global leader with 164.1 million sheep and 138.2 million goats. Other important sheep producers, in order of population, are Australia (70 million), India

\footnotetext{
${ }^{*}$ Corresponding author:

Veysi Acıbuca, Mardin Artuklu University, Kızıltepe Vocational School, Department of Plant and Animal Production/Organic Agriculture PR., 47000, Mardin/Turkey, E-mail: veysiacibuca@artuklu.edu.tr
} 
(61.7 million), and Nigeria (42.9 million). In terms of goat population, China is followed by India (132.7 million), Nigeria (79.3 million), Pakistan (74.1 million), and Bangladesh (60.1 million). Data from 2018 places Turkey eighth in the world with 33.6 million heads of sheep, and twenty-first in the world with 10.6 million heads of goats (FAO, 2018). The same source shows that $74.3 \%$ of the world's sheep population and $94.4 \%$ of the world's goat population exists on the Asian and African continents.

Small ruminant farming is an important activity in all regions of Turkey. It is practiced extensively, usually with low-productivity local breeds, aiming for limited-input production based largely on pasture grazing. According to data collected by the Turkish Statistics Institute (TUIK) in 2019, there are a total of 48.5 million heads of small cattle in Turkey (TUIK, 2019). The Eastern Anatolian region is home to $23.9 \%$ of total small cattle (11.5 million heads), it is followed by the Central Anatolian region with 9.6 million heads (19.9\%) and the Southeastern Anatolian region with 9.4 million heads (19.4\%). The Eastern Anatolian region takes the first place based on sheep population, whilst the Mediterranean region comes first based on goat population. The Black Sea region comes last based on both metrics.

The TRC3 region comprises four provinces (Mardin, Batman, Şırnak, and Siirt) in the Southeastern Anatolian region, where production is mainly agricultural, with insufficient industrialisation and a large rural population. According to 2018 data, agricultural activity makes up $6.2 \%$ of Turkey's total GDP whilst it makes up $11.6 \%$ of the TRC3 region's GDP (TUIK, 2018). 2019 data shows that the TRC 3 region contributes $2.1 \%$ to Turkey's total vegetable production value, $1.8 \%$ to the total animal products value, and $3.2 \%$ to the total live animals value. The region is home to $8.3 \%$ of the country's small cattle population with 4.02 million heads (TUIK, 2019).

The issues faced by cattle farmers in the TRC 3 region differs from the general problems encountered Turkey-wide, as they are related to increased migration to cities from rural areas starting in the 1990s due to security problems in the region, and the inability to make use of pastures and grazing areas at the desired levels due to the same security concerns. For these reasons, the management of both herds of cattle and pasture areas is not at the required level, which hinders the development of small cattle farming. This has also been a setback financially, as husbandry is an important source of income in the aforementioned rural areas. Uzmay (2017) conducted a survey and declared that policies about agriculture had a negative impact on farmers' new investments on agriculture. Ögel (2018) found that 76,1 of small ruminant farms had benefited from agricultural subsidies in Şırnak. Demir and Yavuz (2010) declared that the main information source about government subsidies on animal husbandry was farmers' relatives and other farmers in North East Anatolia.

Adams (206) found out that socio-economics features, such as age, income and number of houseolds of small ruminant producers and agricultural extension activities had an important afccet on small ruminant production level in Ghana.

The main objectives of this study were to develop small ruminant production level with new innovative techniques and encourage people who wants to be a breeder in the region. For this reason, the current structure of small ruminant breeders and their problems and expectations from government were identified and relevant suggestions were made to guide agricultural extension activities and policies.

\section{MATERIALS AND METHODS}

The main material of this study was provided from questionnaires with small ruminant producers in TRC3 Region (Mardin, Batman, Siirt and Sirnak provinces). Also, public and private sector reports, subject matter experts' opinions were included as a material in this study.

The population of this study was all small ruminant farms in TRC3 region. First the number of small ruminant farm and animal numbers were obtained from Provincial Directorates of Agriculture and Forestry and Sheep and Goat Breeders Unions. There are four provinces and 30 districts in the TRC3 Region. Due to time and money constraints and terrorist incidents in some districts, sampling method was used to collect data.

The stratified random sampling method was used in order to increase the accuracy of the obtained data and make sure that the different size of farms can be represented adequately. Stratified random sampling is a method of sampling that involves dividing a population into smaller groups-called strata. In this study, the strata are organized based on the sheep and goat numbers in farms.

The following formula was used to determine the number of samples in each stata (Esin et all., 2001).

$(\Sigma \mathrm{Nh} . \mathrm{Sh})^{2} \quad$ (2) $\mathrm{D}^{2}=\mathrm{d}^{2} / \mathrm{z}^{2}$

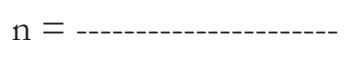

$\mathrm{N}^{2} * \mathrm{D}^{2}+\Sigma \mathrm{Nh} . \mathrm{Sh}$

n: Sample size

Nh: Number of farms in stratum h of the population 
Sh: Standart deviation within stratum h

$\mathrm{Sh}^{2}$ : Estimation of population variance in stratum $h$

$\mathrm{N}$ : Number of farms in population

$\mathrm{D}^{2:}$ Desired variation

$\mathrm{d}$ : Accepted margin of error from the mean (5\%)

$\mathrm{z}$ : z-value from the table

With $95 \%$ of confidence level and 5\% margin of error, the sample size was calculated 333 but 366 farmers were interviewed $(10 \%$ more than the sample size) in case some farmers enable to complete the survey. In Mardin 142, in Siirt 93, in Şrnak 67 ve in Batman 64 farmers were interviewed to collect data.

The questionnaire was construsted depend on previous surveys (Demir, 2009; Kandemir et al., 2015; Adams, 2016;), litreture review and premilinary research of national and international institutions. First pretest was conducted in Mardin with 30 breeders and revised in needed areas. The data were collected between March to September in 2019. The collected data were analysed by using the SPSS 22.0 software. Quantitative variables were analysed via the Kolmogorov-Smirnov test to see whether they fit the normal distribution and found that some variables did not fit the normal distribution. Chi-square test was used to see the differences between socio-economic variables and stratas but some variables did not fit the some assumptions of chi-square. For these variables Kruskall-Wallis H test was applied instead of Chi-square.

In order to determine the factors affecting the adoption of innovation in farms, first innovation adoption groups were formed by using the average scores of farmers' responses. Then, multiple linear regression analyses were used to determine the factors level and discriminant analysis was used to determine the accuracy of the classified innovation adoption groups.

\section{RESULTS AND DISCUSSION}

\section{Socio-economic features}

Most of the farmers (97\%) were male, 92.9\% were married, the mean age was 45.8 and the average number of family members living in the same household was 7.2 individuals. Bakir and Mikail (2018) found that small ruminant breeders age was 47,0 in Siirt, which is similar to our findings. Those educated to secondary school level or below made up $75.7 \%$ of the farmers, whilst those educated above secondary school level comprised $24.3 \%$ and $42.3 \%$ of the farmers had social security.

$40.7 \%$ farmers were found to have a non-agricultural source of income. A chi-squared analysis was conducted to reveal the relationship between the number of animal and nonagricultural sources of income. As a result, the number of animal and non-agricultural sources of income were found not to be independent, and a meaningful difference on the level of 0.01 was discovered between them.

More than half of $(55.9 \%)$ of the farmers had been practicing small ruminant farming for over twenty years. Özsayin and Everest (2019) also found that 50,9\% of small ruminant breeders had an experince over twenty years in Çanakkale, Turkey. This experince year was 25,9 in Mersin, Turkey (Keskin and Bebek, 2018). 46.1\% stated they worked in small ruminant farming for commercial purposes, whilst 33.1\% stated they did it due to not having any other source of income. A meaningful difference on a level of 0.01 was discovered between the number of animals owned by producers and their reason for practicing small ruminant farming. Owners of farms with fewer than 130 heads of cattle were mainly (38.9\%) concerned with providing the animal product needs of their families, while those with larger numbers of small ruminant were more interested in commercial activity.

Huge number of farmers (89.1\%) were found to be members of the sheep and goat breeders' association. Association membership levels increased in correspondence with the number of animals owned.

It was found that sheep farmers in the region placed great importance on the animals' physical features, and when selecting which breed of sheep to farm, their number one priority was to "select the type of breed that has been traditionally preferred". Only 1.1\% of the farms had modern facilities, whilst 4.6\% used tents and 94.3\% used traditional sheep pens. All of the farmers which use tents were sheep and goat owners who practiced nomadic or semi-nomadic husbandry.

Vegetable production and existence of fields used for grazing and growing coarse fodder were researched, and $52.5 \%$ of farms were found to own land which ranged from 5-750 decares in area. The median area of land owned by the farms was 64.2 decares. Only $7.2 \%$ of farms which owned land produced coarse fodder, while $92.1 \%$ chose to grow other vegetable products on their land. Karakus and Akkol (2013) also found that only 12,2\% of small ruminant breeders produce fodder in Van, Turkey.

Only $8.2 \%$ of farm activities were found to be conducted by female children, $21.2 \%$ by male children, $27.9 \%$ by adult women and $42.6 \%$ by adult men. Women worked most intensively in dairy production (99.1\%) and milking $(98.6 \%)$. 


\section{Benefits derived from small ruminant farming}

Benefits derived from small ruminant farming (daily sales, meat sales, manure sales, livestock sales, household consumption, sales to meet emergency cash needs, and motivation to remain in villages) by farmers, and the greatest benefit was found to be product consumption to meet household needs at $100 \%$. This was followed by livestock sales $(92.6 \%)$, dairy sales $(91.8 \%)$, sales to meet emergency cash needs $(64.5 \%)$, motivation to remain in villages $(52.7 \%)$, meat sales $(9.6 \%)$, manure sales $(2.5 \%)$, and by-product (wool, leather, skin) sales $(11.5 \%)$.

Most of the farmers (98.6\%) were found to have their livestock registered at the Provincial/District Departments of Agriculture and Forestry, and 88.5\% benefitted from government subsidies. Those who choosed not to use subsidies cited the following reasons: the subsidy amount was insufficient (3.8\%), the lengthy bureaucratic process $(3.8 \%)$, did not know how to apply for subsidies $(1.6 \%)$, not awarw of the subsidies $(1.4 \%)$ and not eligible for subsidy $(0.8 \%)$ because of unregistered animals. Farmers accessed information about the subsidies from staff at the Provincial/District Departments of Agriculture and Forestry (48.8\%), other producers $(42.4 \%)$, union stadd $(22.7 \%)$, radio/ television/internet $(16.9 \%)$ and lastly, ministry personnel visiting the village $(7.8 \%)$.

\section{Animal well-being practices}

One of the primary factors influencing success and sustainability in small ruminant farming is animal health and well-being practices. A timely and efficient schedule of animal healthcare leads to increased feeding and breeding capacity, which contributes significantly to the profitability of a business. The most often encountered animal diseases in the businesses studied were Brucellosis (61.7\%), diarrhea (36.4\%) and parasites (31.4\%).

When questioned regarding the biggest obstacles they faced in terms of animal healthcare, $47.5 \%$ of farmers cited insufficient access to veterinary care, $27.9 \%$ said ineffective medication and 19.1\% said lack of knowledge regarding animal well-being.

\section{Expenses and credit use}

Small ruminant farming is the lowest-cost husbandry activity in Turkey as it is largely based on pasture feeding (Aksoy and Yavuz, 2012), however, it is also known that the greatest expense for small ruminant farmers is animal feed (Demir, 2009). The farmers ranked their expenses in order of cost as follows: animal feed (100\%), medication $(86.9 \%)$, veterinary care $(50.8 \%)$, shepherding costs $(10.7 \%)$ and pasture costs $(9.8 \%)$.
The use of industry-related loans for farmers engaged in small ruminant farming was found to have a positive effect on productivity levels. Farmers that use agricultural loans are expected to have bigger production outputs. Only $30.3 \%$ of farmers were found to have taken on loans/debts in the past three years. Öğel (2018) found very similar result in Şırnak which was 31,2.

\section{Information sources}

One of the most influential factors in increasing agricultural production and elevating productivity and quality of products is agricultural information sharing services. According to data obtained by this study, small ruminant farmers' preferred sources of information are as follows: Provincial/District Departments of Agriculture, other farmers, private veterinarians, television, internet, cattle markets, unions, radio, conferences, and universities/ research institutions. A chi-squared analysis was conducted to reveal the relationship between age, education status, and accessing online information, and it was found that a higher educational level correlated to a preference for online sources of information ( $\mathrm{p}=0,000)$; it was also found that farmers who were younger primarily used the Internet as a source of technical knowledge $(p=0,000)$. Karakaya and Kizıloğlu (2014) found that majority of farmers were using Provincial/District Departments of Agriculture as a main information source.

\section{Adaptation to innovations}

Agricultural innovations contribute significantly to raising living standards for rural populations. Farmers adopting new technologies and practices not only helps decrease production-associated risks but also contributes to lower costs and increased profits. A five-fold likert scale was used to ascertain farmers' implementation of new information and technologies. It was found that $53.5 \%$ of farmers limed their sheep pens, $31.1 \%$ kept registers, $30.9 \%$ disinfected their sheep pens, $20.2 \%$ tried cross-breeding, $19.7 \%$ had their animals insured, $12.6 \%$ received consultation services, $7.7 \%$ grew fodder plants, $3.3 \%$ used automated milking units, and $1.6 \%$ had a manure tank/well on their farms.

For every innovation mentioned, it was discovered that owning a larger number of animal was associated with higher levels of innovation adoption; there was a meaningful difference $(p<0,01)$ between levels for all innovations except the use of manure tanks and liming sheep pens. Farms with more than 260 heads of animal differ from the rest in terms of adopting new innovations.

Yener (2017) conducted a survey in Konya and found out that age, status of following innovations, affects of other farmers and income level had a positive affect on farmers adoption of new techniques and technologies. 


\section{Experienced problems}

The biggest issue facing farms was "inability to find shepherds" at $66.9 \%$, followed by low milk production (57.4\%), low meat production (54.4\%), lack of information regarding small ruminant farming (53.6\%), lack of bookkeeping $(36.6 \%)$ and a low ram/billy goat population (26.5\%). Tüfekci (2020) declared that animal health (45,0\%) was the most important problem in Yozgat.

Foremost among animal health issues are high vaccine/ medication costs $(95.4 \%)$. This is followed by high lamb/ kid mortality (61.7\%), failed insemination (45.1\%) and lack of sheep pen hygiene $(44.8 \%)$. Marketing problems were studied under two categories: milk/dairy product pricing issues and livestock sales issues. Most of the farmers $(82.2 \%)$ stated that milk and dairy prices were too low, whilst $72.7 \%$ of farmers confirmed they encountered problems in livestock sales.

Other problems encountered in the region by small ruminant farmers were stated to be high fodder prices $(99.2 \%)$, insufficient subsidies (94.3\%), lack of pastures $(75.7 \%)$, lack of farmer education $(74.0 \%)$, inefficient producer unions $(66.1 \%)$ and inadequate industry-related loans $(57.1 \%)$.

\section{Affecting factors of adoption level}

To determine the level of adoption, nine innovative technique were selected and scored with three point Likert type scale. Farmers' responds added up and divided by nine to define the adoption level. In order to determine the factors that affect the adoption level multiple linear regression analysis was performed. Dependent variable was adoption level in three groups.

A variance inflation factor (VIF) provides a measure of multicollineratity among the independent variables in a multiple regresion model. It is known that the high VIF value means less relaible of the regression results. In general, VIF above 10 indicates high correlation (Albayrak, 2008). As seen from the Table 1, there is no multicollineratity because VIF values are less then 10 .

Durbin-Watson test, which is used to detect the presence of autocorrelation in the residuals of regression. It was found 1,896 that means there is no autocorrelation.

Eight out of twelve variables fitted in the regression model was ssignificant at various levels. The F-statistic was significant at $1 \%$ level of significance indicating goodness of fit. The coefficient of multiple determination $\left(R^{2}\right)$ value was estimated to be 0,470 this implies that $47,0 \%$ of total variation in the output of small ruminant production was accounted for by the independent variables that
Table 1: Variance inflation factors

\begin{tabular}{lc}
\hline Variable & VIF \\
\hline Age & 3,504 \\
Education level & 2,562 \\
Rearing experience & 2,849 \\
Rearing reason & 1,105 \\
Milking way & 1,123 \\
Produced products & 1,126 \\
Benefits of rearing & 1,120 \\
Animal well being practices & 1,451 \\
Experienced problems & 1,112 \\
Communication behavior & 1,435 \\
Number of animal & 1,438 \\
Fold type & 1,171 \\
\hline
\end{tabular}

Table 2: Multiple linear regression results of factors affecting adoption

\begin{tabular}{lccccc}
\hline \multirow{2}{*}{ Model } & \multicolumn{2}{c}{ Unstandardized } & & \multicolumn{2}{c}{ Standardized } \\
\cline { 2 - 3 } \cline { 5 - 6 } & B & Std.Error & & Beta & Sig. \\
\hline Constant & 1,214 & 0,220 & & $-0,155$ & 0,000 \\
Age & $-0,004$ & 0,002 & & 0,068 & 0,033 \\
Education level & 0,019 & 0,017 & & 0,051 & 0,271 \\
Rearing experience & 0,011 & 0,014 & & $-0,091$ & 0,439 \\
Rearing reason & $-0,025$ & 0,011 & & 0,105 & 0,025 \\
Milking way & 0,176 & 0,069 & & 0,085 & 0,011 \\
Produced products & 0,029 & 0,014 & & $-0,003$ & 0,039 \\
Benefits of rearing & $-0,003$ & 0,049 & & 0,348 & 0,949 \\
Animal well being & 0,259 & 0,035 & & 0,058 & 0,000 \\
practices & 0,058 & 0,041 & & 0,218 & 0,160 \\
Experienced problems & 0,200 & 0,043 & & 0,081 & 0,000 \\
Communication & 0,029 & 0,016 & & $-0,094$ & 0,081 \\
behavior & $-0,104$ & 0,046 & & 0,025 \\
Number of animal & & & & \\
Fold type & & & & \\
\hline
\end{tabular}

$R^{2}=0,470 R^{2}(\operatorname{adj})=0,452$ Durbin-Watson=1,896 F=26,125

Table 3: Anova Test Result

\begin{tabular}{lccccc}
\hline Model & SS & df & MS & F-Value & P-Value \\
\hline Regression & 15,254 & 12 & 1,271 & 26,125 & 0,000 \\
Residual & 17,176 & 353 & 0,049 & & \\
Total & 32,430 & 365 & & & \\
\hline
\end{tabular}

were fitted into the model. The regression result shows that variables age, rearing reason, milking way, produced products, animal well-being practices, communication behavior, number of animal and fold type were statistically significant at different levels. The Anova test result is seen in Table 3.

\section{CONCLUSION}

A high median age and low education level amongst the farmers is in line with the general features of farmers in Turkey, and the results obtained confirm that age and education level play a significant role in adopting new innovations and therefore increasing productivity. Despite having a high rate of DKKYB (Turkish Sheep and Goat Breeders' Association) membership, only $10.9 \%$ producers were found to make use of the association's consultation services. 
Majority of producers (88.5\%) benefit from small ruminant breeding subsidies, whilst the same rate is $64.8 \%$ for farmers with 130 or fewer heads of small ruminant. Due to the fact that most small farms practice small ruminant breeding to meet household needs, the income they derive from their work and other benefits are naturally low.

Results of the regression analysis show that farmers which possess a large flock, a modern/semi modern sheep pen, and are owned by young farmers who are highly adept at communication, practice animal well-being, and whose primary aim is commercial have a higher rate of embracing innovation.

In conclusion, it was found that small ruminant farming in the TRC3 region are primarily managed as traditional family members and that a significant portion of producers use non-rational methods when it comes to selecting and managing livestock, ensuring animal health and well-being, and providing feed. Despite this, it was found that small ruminant farming is a vital financial activity in the region, and that farms with larger populations of animals had a higher rate of adapting to innovations.

\section{Recommendations}

It will be beneficial to suggest highly educated young individuals to practice small ruminant breeding and for husbandry projects to target young people living/wanting to live in the rural areas. There are agricultural engineers and/or veterinarians who provide advisory services in every branch of the association. Producers must be reminded that association membership is not solely a mandatory hoop to jump through to access subsidy payments, and that its main purpose is educating farmers and raising awareness regarding productivity-increasing measures, how to fight disease, etc. To ensure this, the efficiency of existing association branches must be reviewed/examined, and they must be transformed into more actively functioning structures. If producers take steps to specialise in small ruminant breeding, their opportunities for benefitting from subsidies and grants will increase, as will their income due to a shift in perspective which will allow them to regard their work as commercial. Targeting producers with low adoption rates of innovation as a priority in publications catered to small ruminant farmers will both decrease the costs of publication and increase the level of early adapters, thus facilitating the easy/quick influencing of other farmers.

\section{CONFLICT OF INTEREST}

The authors declare that there are no conflict of interest.

\section{ACKNOWLEGMENT}

This project has been supported by Cukurova University. Project No: FDK-2018-10788

\section{Authors' contributions}

Veysi Acıbuca: Topic selection, literatüre review, sampling method, data collection and analyses, writing. Dilek Bostan Budak: Topic selection, literatüre review, sampling method, data analyses, review and editing

\section{REFERENCES}

Adams, F. 2016. Socio-Economic analysis of small ruminant livestock production in Northern Ghana (Doctoral dissertation). Kwame Nkrumah University of Science and Technology. Kumasi, Ghana.

Aksoy, A. and F. Yavuz. 2012. Analysis of the reasons of farmers to quit small ruminant production: The case of Eastern Anatolia Region. Anatolian J. Agric. Sci. 27: 76-79.

Albayrak, A. S. 2008. Weighted regression analysis and an application for the alternative of least squares technique in the case of changing variance. Adm. Sci. 10: 111-134.

Bakır, G. and N. Mikail. 2019. Structural situation of sheep and goat farms in Siirt. J. Ataturk Univ. Facult. Agric. 50: 66-74.

Delgado, C., M. Rosegrant, H. Steinfeld, S. Ehui and C. Courbois. 2001. Livestock to 2020: The next food revolution. Outlook Agric. 30: 27-29.

Demir, N. 2009. Regional Comparative Analysis of the Effects of Support Policies on the Animal Husbandry Sector. Atatürk University Institute of Science PhD Thesis, Erzurum.

Demir, N. and F. Yavuz. 2010. Interregional comparative analysis of farmers' approaches to livestock support policies. J. Atatürk Univ. Facult. Agric. 41: 113-121.

Esin, A., M. A. Bakır, C. Aydın and E. Gurbuzsel. 2001. Basic Sampling Methods (Translation from Taro Yamane). Literature Publications, Istanbul.

FAO. 2014. Food and Agriculture Organization of United Nations. Sustainable Livestock Production Systems. Available from: http://www.fao.org/livestock-systems/en. [Last accessed on 2019 Apr 16].

FAO. 2018. Food and Agriculture Organization of United Nations. Available from: http://www.fao.org/faostat/en/\#data/QC. [Last accessed on 2020 Apr 03].

Kandemir, C. I., H. I. Alkan, H. B. Yılmaz, T. Unal, N. Taskın, N. Kosum and A. Alcicek. 2015. General situation and development possibilities of samll ruminant farms according to their geographical locations in Izmir region. Anim. Prod. 56: 1-17.

Karakaya, E. and S. Kızıloğlu. 2014. organizational structure of ovine farms: The case of Bingöl province. Turk. J. Agric. Nat. Sci. 1: 552-560.

Karakus, F. and S. Akkol. 2013. A study on the current situation of sheep farms in Van and determination of problems affecting productivity. J. Sci. Ins. 18: 9-16.

Keskin, M. and D. T. Bebek. 2018. Current status, some yield and structural properties of sheep breeding in Mersin. J. MKU Facult. Agric. 23: 315-323.

Ögel, H. 2018. Economic Structure and Problems of Ovine Breeding in Şırnak Province (Master's Thesis). Süleyman Demirel University, Institute of Science and Technology, Isparta. 
Özsayın, D. and B. Everest. 2019. Socio-economic structure of farmers that make sheep breeding and practices related to their sheep breeding activities. KSI Univ. J. Agric. Nat. 22: 440-448.

Sakarya, E. and E. Aydın. 2010. World Beef Production, Consumption and Imports by Turkey of Live Animals and Beef Trade. Ankara Commodity Exchange Reports.

Thornton, P. K. 2010. Livestock production: Recent trends, future prospects. Philos. Trans. R. Soc. B Biol. Sci. 365: 2853-2867.

Tufekci, H. 2020. Structural status and development opportunities of ovine breeding in Yozgat province. Anim. Prod. 61: 91-100.
TUIK. 2018. Turkish Statistical Institute. National Calculations. Available from: http://www.tuik.gov.tr/UstMenu.do?metod=temelist. [Last accessed on 2019 Jan 24].

TUIK. 2019. Turkish Statistical Institute. Crop and Animal Production Values. Available from: http://www.tuik.gov.tr/UstMenu. do?metod=temelist. [Last accessed on 2020 Apr 02].

Uzmay, A. 2017. Determination of producer views on the effects of policies Implemented in the livestock sector on dairy farms: The example of İzmir province. J. EU Facult. Agric. 54: 167-175. 